This is an electronic reprint of the original article. This reprint may differ from the original in pagination and typographic detail.

Please cite the original version: P. Tani, K. Komulainen, T. Ylikoski (2018) Building bridges between vocational education, upper secondary and higher education - a Common Digital Learning Environment (CDLE), ICERI2018 Proceedings, pp. 9948-9952.

doi: $10.21125 /$ iceri.2018.0085 


\title{
BUILDING BRIDGES BETWEEN VOCATIONAL EDUCATION, UPPER SECONDARY AND HIGHER EDUCATION - A COMMON DIGITAL LEARNING ENVIRONMENT (CDLE)
}

\author{
P. Tani, K. Komulainen, T. Ylikoski \\ Laurea University of Applied Sciences (FINLAND)
}

\begin{abstract}
Finland, the country famed for its education, is seeing a decreasing trend in higher education. The number of students who proceed to higher education has developed a downward trend during the last few years. Also, the length of studies in higher education is longer than in other European countries. The Ministry of the Education and Culture has challenged universities of applied sciences to develop innovative ways to shorten the overall study time. At the same time, many students starting their higher educational studies are older than in other European countries.
\end{abstract}

The aim of this study is to describe a development project between Laurea University of Applied Sciences and several vocational secondary schools and general upper secondary schools in Finland's metropolitan area. We have co-created a common digital learning environment which is conceived as an ecosystem - a learning environment consisting of learning tools and components that adhere to common learning goals. In the system, secondary school students have the option of taking some studies from Laurea. This gives them a head start in their future university level studies and helps to bridge the transition.

The developed "common digital learning environment" (CDLE) is an ecosystem more focused on learning rather than administration. The purpose of the CDLE has been to shorten overall study time and to give vocational students an option to try higher education studies as a part of their vocational educational studies or studies at upper secondary. The CDLE model has shown that it is possible to integrate higher educational studies with secondary level studies.

This article discusses ways of integrating studies between educational levels via a digital learning ecosystem. In this article, we will present a concrete model of the CDLE. This model is ecological, economical, reachable and student centred. The findings of the project are promising. So far, we have opened the CDLE for almost all of Laurea's bachelor programs.

In the future we aim to make the CDLE available for master's level programs as well. We conclude that there are different ways to shorten study times, intensify studies between levels of degrees and to give a chance to try higher educational studies using digital learning opportunities, such as the common digital learning environment CDLE.

Keywords: E-learning, vocational school, higher education, upper secondary, study path, vocational education

\section{INTRODUCTION}

Education is in a transition. Digitalisation challenges students and teachers alike as capabilities needed tomorrow are rapidly shifting. At the same time, the need for educated workforce for the future workplace is increasing. Finnish education is known for its high quality - yet Finns tend to graduate to employment late in comparison to other European countries. In addition, higher education degrees are on a downward trend in Finland. At the same time, the higher education trend is on a steep incline example for in Asia.

One issue that these observations have given rise to, is the need for facilitating the transitions between educational levels. This is expected to speed the transition from secondary education to universities and improve the overall number of young people opting for higher education; both of which are the objectives of the Finnish Government's programme for the future of education. One of the strategic key projects is 
improving knowledge and education, also seen in the vocational secondary education reform in Finland. The model we present in this paper was born out of these needs, answers to the call of the reform, and helps in an accelerated transition to student employment. (1)

Laurea University of Applied Sciences started a cooperation with several vocational secondary schools in 2015. One of the fruits of the cooperation were our Digital Pathway Studies. These are a joint educational offering where a student taking vocational secondary studies also takes some higher education courses as part of her vocational degree (2). We approached the development from a cocreation perspective, fostering communality and encouraging student involvement. The Digital Pathway relies on guidance, which is provided by support from the secondary school, the university, and peer support.

Positive results with the Digital Pathway resulted in an expansion from vocational schools into academic upper secondary schools ("high schools") as well (3). As these are on the secondary level in the Finnish education system, we will use the term "secondary schools" for both in this text. The Pathway grew and evolved into a holistic learning ecosystem which we have termed "Common Digital Learning Environment", or CDLE for short.

There is a societal need in Finland for educational innovations that help bridge university studies into secondary vocational studies and upper secondary academic studies. The reform of vocational secondary education and the reforms (4) in general upper secondary education require secondary level schools to introduce university studies in their curricula. This is also a factor in the secondary education financing system.

\section{DESCRIPTION OF THE CDLE MODEL}

The Common Digital Learning Environment is based on the fundamental assumption that students have an idea of the career and profession they want to pursue in the future. Studies in the CDLE model are specific to the degree. As a result, e.g. a student in a practical nurse program who has ambitions to continue to a Bachelor of Health Care, can take these studies as part of her secondary vocational studies. She can have these studies recognised as part of her future nursing studies in the university. As a result, the overall length of studies shortens and the transition to employment accelerates.

The CDLE is available in the following degrees in Laurea: nursing, social services, correctional services, beauty and cosmetics, business, business information technology, restaurant entrepreneurship and safety management. Many of the degree programs are highly attractive and entrance is very difficult. The CDLE serves to prepare for the entrance exam as well. It is also possible for general upper secondary students to use our CDLE studies to assist in preparation for other universities' entrance exams, such as for medical schools.

A crucial part of the innovation is that it is a fruit of cooperation and co-creation with experts in secondary schools. Their commitment and understanding of introducing university studies in secondary education is crucial in ensuring student success.

The CDLE model is based on an agreement that assigns responsibilities and helps train study counsellors to work with the model framework. Once the agreement is completed, Laurea assigns peer tutors who also have a similar secondary background as the beginning students do. A lecturer coordinates the studies and maintains a close cooperation with Laurea as well as partner organisations.

Prior to our CDLE and the Digital Pathway, many attempts to integrate university studies with secondary studies failed. The reasons of prior failures are threefold: first, rising costs have caused issues, second, the long distances between the schools and universities have been problematic in a geographically large country, and third, the timing of the studies have often collided.

To counteract these, the CDLE takes place on a digital platform and is completely free of time and space restraints. Hence, none of the previous hurdles cause issues in the model. Secondary level students can take their studies simultaneously with university students sharing the same goals, requirements and assessments. 


\subsection{The educational and social function of the CDLE}

The CDLE has an impact on the educational system as well as social functions, such as expanding the social circles of the participating students. In analysing the educational and social function of the CDLE, we first need to identify the key targets of the current educational system. These brought about a radical change in societal tendencies and as a consequence, in education. One manifestation of this is the vocational education reform in Finland (1). According to our project, the crucial points are: transformation of education, co-creation, the educational offering, the identity of a university student and tutoring.

\subsubsection{Transformation of traditional concept of education to new student-oriented models}

The first point relates to a shift in education from lecturing and disseminating knowledge into cooperation, co-creation and coaching. There must be a strong link between the secondary schools and Laurea to have a common vision and common learning goals. The CDLE has been built using cocreation, where students have been playing a major role. The use of digital devices, like smartphones, gives a lot of flexibility to study.

Transformation from more traditional teaching to newer interactive and digital models is very demanding for teachers. The CDLE fosters an open and dynamic mentality in participants; making them capable of evolving with the evolution of education. In a school, which is equipped for the CDLE, the fundamental knowledge cannot be defined as definitive disciplines; but rather as inter-disciplinary skills involving the co-operation of different disciplines and ways of educating.

According to our project, the cognitive, social, emotional and relational aspects have simultaneously evolved in the didactic environment of the CDLE. This is apparent in the evaluation feedback that students give. Due to the change in the concept of education, we have gained a number of new enthusiastic students to experiment with higher education.

\subsubsection{CDLE and co-creation}

Today, the success of most educational organisations is dependent on the student's involvement. Active young people are well aware that they can contribute to value creation at certain points of the future school and learning environment. This has led to responsive behaviour, which in turn leads to open innovation and consequently, to co-creation.

Co-creation is collaboration between educational organisations and the students and the whole community that aims to produce something new. Co-creation approaches teacher-student interaction from a new angle, one that depicts a paradigm shift to the experience-centric view of value from a teacher-centric or learning-centric view. One result involves improved communication between the teacher and students. It is clear that any educational organisations building new services such as the CDLE, are prioritising students end their experience.

\subsubsection{CDLE and educational offering}

The CDLE and its development has societal goals in addition to learning goals. Finnish legislation has been renewed with the aim of secondary academic or vocational students being able to include European EQF6 level studies in their secondary degree.

Every student applying to Laurea has a secondary level degree in either the academic path (general upper secondary) or the vocational path (vocational secondary). The vocational path is currently more common in Laurea, with approximately $60 \%$ of the applicants having a vocational degree.

However, although these secondary level degrees have an equal status, all students do not have equal capabilities for university studies. The CDLE offers a low threshold way of trying out one's capabilities and motivation beforehand.

On the CDLE platform, Laurea offers studies in substance matter as well as university study skill building. A combination of these helps the student assess her own university eligibility and skills and gain an understanding of what studying in a university actually entails. 
Acceptance in the CDLE requires a personal study plan (PSP) for each secondary level student and having the plan accepted in her own school. The plan helps ensure the student's motivation and having the necessary requirements for the CDLE. For this reason, the CDLE is not an open environment. Participation requires that the student consults a teacher in her secondary school first.

\subsubsection{The identity of a university student}

In our project we learned that the identity of a university student is an important factor for study progress. Laurea's approach is to treat secondary school CDLE students as equal to our own university students. Having university student rights also ensure proper guidance during studies and that the study records are collected appropriately.

CDLE students get all the same access and services to databases and learning environments; and consequently, are able to create an identity of a university student. This helps to facilitate student networking, communication on closed social media platforms, and the possibility to access other digital learning environments that Laurea offers.

\subsubsection{Tutoring and peer support}

According to our experience, students have built up their own social communities to support them in their studies. To reach this goal, it is important to support group formation with other students. Laurea offers both student-tutor as well as teacher-tutor services to CDLE students. The support of the student's own second degree school is also crucial for progress in studies. This demonstrates our approach: We take the CDLE students as full-fledged members of the university community. The student-tutor is a university student who has previous studies in a similar secondary school as the group in question. This helps the student assimilate with the tutor as see her as a role model. It also helps in building a shared understanding.

Finland's secondary education has been subject to a large reform recently. In assessing secondary education and making financing decisions, the Ministry of Education assesses how many students continue their studies from secondary level studies to universities. The CDLE serves to support this directly. It is also an excellent marketing channel for any secondary school student. Hence the ecosystem benefits all parties.

University entrance exams are under a reform in Finland, where the emphasis is moving from entry exams to previous school certificates. A separate quota is allocated for first time applicants. The purpose of this reform is to enable faster access to university studies and hence accelerate the transition to employment. The reform also seeks to improve equality in opportunities, cost efficiency of the student selection process, and a more effective allocation of a university's new applicant quotas.

Laurea is one of the most attractive universities in Finland. Only a small share of those interested in studying with us are accepted due to the large number of applicants. However, a student taking open university studies for 60 credits, can apply for entrance to the degree program in a separate application process. Here, the CDLE can serve as a stepping stone for university entrance. The student can begin her future university studies first in the CDLE model, continue in the open university, and the apply for a degree program after the required 60 credits have been accumulated. This has a societal impact from the perspective of life-long learning.

\section{ASSESSMENT OF THE PROJECT}

The CDLE model answers to the call of the vocational education reform in Finland pertaining to individualisation of studies, an easier transition to higher education, and the development of digital learning environments (4).

The model we first piloted in 2015 has been ahead of its time: the key benefits of the model have become the requirements in new legislation. The CDLE meets the Ministry of Education's recent demands perfectly. The head start has given us an opportunity to offer our regional partners an operating solution to build on and to expand on. 
New challenges arose from general upper secondary schools' joining the CDLE. We have needed to think of arguments for upper secondary students to consider studies in a university of applied sciences. The typically more desired path from these general upper secondary schools is to scientific universities. On the other hand, only $3 \%$ of vocational school students continue to scientific universities (5). As a result, participation among vocational students has been far more active in the CDLE. However, as all general upper secondary students are not accepted to scientific universities, the universities of applied sciences need to focus their efforts in locating these people.

\section{CONCLUSIONS AND FUTURE PLANS}

In the near future we are planning to expand the CDLE model to our masters' programmes. In Finland students have the opportunity to study for a masters' degree in two paths: in traditional, scientific universities and also in universities of applied sciences. Most of those students are working and have families and as distances to universities in Finland tend be quite long, there is need to improve this way for trying out studies of masters' programmes. On the other hand, we could also offer CDLE studies to current bachelor students while they are studying their current degrees.

We have had the CDLE in operation for three years. So far, we do not have gathered data on where the participating students have actually continued after vocational or general upper secondary studies. Therefore, we do not have information how the CDLE model has worked to shorten the study time and how many students have continued their studies to scientific universities or universities of applied sciences.

In the future, it would be beneficial to spread the CDLE model to all over Finland. This model is suitable especially for regions that do not do not have their own university. On the other hand, there are also possibilities to spread the model to Europe as well, because we do have many international, English programmes like the nursing degree program. This might be the way to increase number of applicants to our international degrees.

The ongoing reform in Finnish vocational education poses a potential threat that may deepen the gap between students in vocational schools and general upper secondary schools. Vocational educational is going to be more work-oriented than it has been. Students might face challenges when they apply to higher education which requires theoretical skills. Considering this development, the CDLE is very welcome and necessary in Finnish vocational education. On the other hand, vocational education institutes get more funding if their students continue their studies in higher education, and, as noted, the traditionally more lucrative path from vocational schools is to universities of applied sciences (5).

Despite all the changes in higher education, one element seems to stay constant: the need and desire for collaboration across institutions and we need to offer new and more flexible ways to study.

\section{ACKNOWLEDGEMENTS}

We would like to thank all our partners for their open-minded attitude to develop new ways to integrate higher educational studies to vocational and general upper secondary studies.

\section{REFERENCES}

[1] Government action plan 2018 - 2019. Finland, a land of solutions, 23 September, 2018. Retrieved from http://urn.fi/URN:ISBN:978-952-287-584-6

[2] P. Tani, K. Komulainen, T. Eloranta, S. Gustafsson and T. Ylikoski. "Facilitating the transition from vet to higher education through the "study path"." $8^{\text {th }}$ International Conference of Education, Research and Innovation. Seville, Spain. 18-20 November, 2015.

[3] K. Komulainen, P. Tani and T. Ylikoski. "Facilitating the transition to higher education with a digital pathway." $10^{\text {th }}$ annual International Conference of Education, Research and Innovation. Seville, Spain, 16-18 November, 2017. 
[4] Reform of vocational upper education. 24 September, 2018. Retrieved from https://minedu.fi/en/reform-of-vocational-upper-secondary-education

[5] M. Nylund, P.Å. Rosvall, E. Eiriksdottir, A.S. Holm, U. Isopahkala-Bouret, A.M. Niemi, and G. Ragnarsdottir. "The academic-vocational divide in three Nordic countries: implications for social class and gender," in Education Inquiry, 2018. Vol.1, pp. 97-121, 2018. 